\title{
Evaluation of Performance of MLP Neural Networks and RBF Neural Networks in Adjusting Time Series of the Development of the Trade Balance between the USA and the PRC
}

\author{
Jaromír Vrbka ${ }^{1}$, Petr Šuleřํ, Veronika Machová ${ }^{1}$, Jakub Horák ${ }^{1}$ \\ ${ }^{1}$ Institute of Technology and Business in České Budějovice, School of Expertness and \\ Valuation, Czech Republic
}

\begin{abstract}
Artificial neural networks are widely used for predicting values, for solving possible future problems and are able to provide various solutions in problem estimation, regression or optimisation. They are useful for predicting time series too. The aim of the paper is to analyse and evaluate the performance of multilayer neural networks (hereinafter referred to as "MLP") and neural networks of radial basis function (hereinafter referred to as "RBF) in adjusting time series on the example of the trade balance between the United States and the People's Republic of China. Regression was performed using neural structures. We generated multilayer perceptron networks and neural networks of radial basis function and we generated two sets of artificial neural networks. Time was the continuous independent variable. We determined the trade balance of the USA and the PRC as a dependent variable. We can state that due to the great simplification of reality, it is not possible to predict the emergence of extraordinary situations and their impact on the trade balance of the USA and the PRC. We can state that when an adjusted time series is derived from a single variable, time, RBFs perform better than MLPs. In order to make the prediction more accurate and its calculation easier, it seems appropriate to use RBF networks, which brings a relatively high degree of accuracy.
\end{abstract}

Keywords: multilayer neural networks, RBF, trade balance, future development prediction, USA, People's Republic of China, correlation coefficient 


\section{Introduction}

The aim of the paper is to analyse and evaluate the performance of multilayer neural networks and neural networks of the radial basis function in adjusting time series on the example of the trade balance between the United States of America and the People's Republic of China. No known author deals with the topic as such. However, there are a number of studies that address either the topic in general without a given location or a comparison between other countries. Examples of solutions of individual authors will be gradually revealed in the following text.

Rodrigues et al. (2019) state that through the forecast of time series it is possible to predict future values according to previously observed values. Accurate time series prediction is important for a wide range of different areas.

Artificial neural networks are currently widely used in various technical applications and are becoming a common method for providing various solutions in the field of optimisation, regression and problem estimation. Vochozka (2017a) use multilayer perceptron networks (MLP) and neural networks of radial basis functions (RBF) to determine the relationship between the volume of debt and the economic result of industrial enterprises. The authors analysed the cost-to-profit ratio using three profit categories - operating profit, EBIT and EBT. However, the correlation was not confirmed. In all cases of profit, it can be stated that there is no dependence between interest and the amount of profit. Neural networks also seem to be one of the methods of optimising company inventory. They are useful for predicting time series. Vochozka (2017b) tries to verify the possibility of using neural networks for inventory management on the example of a specific company. Neural networks also seem to be one of the methods of optimising company inventory. They are useful for predicting time series. The datafile contains time series of the inventory of a specific company for the last two years. The data is fitted to a curve which deviates from the actual data and which may also predict the future development of inventory stock. Neural networks, specifically multilayer perceptron networks, were used to obtain the regression curve. Based on the neural structure, the company can predict not only the future state of inventory, but also its movement over time.

Let us go back to measuring the trade balance. This represents one of the best analyses and economic relations of the country. It serves as a monetary expression of economic transactions between a certain country and its foreign partners in a certain period. Rowland et al. (2019) aimed to compare the accuracy of time series adjustment using regression analysis and neural networks on the example of the trade balance of the Czech Republic and the People's Republic of China. Optically, the LOWESS curve was the best out of the linear regression, followed by the smallest square curve by negative exponential smoothing and the curve obtained by the smallest square weighted distance. Of the neural networks, the network 5.RBF 1-24-1 has proven to be the most useful in practice. If we look at the performance in terms of the correlation coefficient, the neural network 5.RBF 1-24-1 remains applicable. 
Vochozka and Sheng (2016) use artificial neural networks to predict potential financial problems in transport companies in the Czech Republic. Data on all companies involved in transport and forwarding in the Czech Republic for the period of 2003-2013 were used to model a specific neural network. The following networks were used to model a neural network: Linear network, probabilistic neural network PNN, generalised regression neural network GRNN, radial basis function network RBF, three-layer perceptron network TLP and four-layer perceptron network FLP. The result of the analysis was a specific model of an artificial neural network. The neural network is able to determine with more than ninety percent accuracy whether a company is able to overcome potential financial problems, whether the company could go bankrupt within a few years, or whether the company could go bankrupt within one calendar year.

Wedding and Cios (1996) describe a method for using Radial Basis Function (RBF) neural networks to generate certainty factors along with normal output. When the RBF output with low values of certainty factors is disabled, the overall accuracy of the network increases. In this article, RBF networks are used in a time series application. RBF neural networks are trained to produce both time series forecasts and certainty factors. Their output is then combined with Univariant Box-Jenkins (UBJ) models to predict future data values. This combined approach improves the overall reliability of time series prediction.

According to Kleštik (2013), artificial neural networks are computational models inspired by biological neural networks, which are used for a number of different areas. At present, neural networks are used mainly for predicting values, for solving possible future problems and are able to provide various solutions in problem estimation, regression or optimisation. Liu et al. (2009) used neural networks with radial basis functions to predict exchange rates. According to their results, it can be stated that the performance of RBF neural networks for prediction is effective and acceptable.

In their contribution, Machová and Vochozka (2019) analyse the development of Unipetrol's stock prices on the Prague Stock Exchange using artificial neural networks, both MLP and the radial basis function RBF networks. They concluded that in practice the MLP is applicable for a one business day forecast. Zhang et al. (2001) investigate the ability of neural networks for linear time series predictions. In practice, it is often difficult to determine whether the basic data generation process is linear or not. Fajardo-Toro et al. (2019) focus on models and techniques for time series predictions that show a comparison of the behaviour of recurrent neural networks against other statistical techniques and different neural network architectures, such as the multilayer perceptron MLP networks, etc. Chang (2011) deals with artificial neural networks, decision trees and a hybrid model of ANN and decision tree. He concluded that, compared to the other two methods, ANN is a more stable method for predicting stock prices in a volatile stock market after the crisis.

Vrbka et al. (2019) compare the accuracy of time series adjustment using regression analysis and neural networks on the example of the trade balance between the EU and the People's Republic of China. The development over time is interesting. The most suitable 
curve is selected from linear regression and three useful neural structures are selected from neural networks. Of the neural networks, three of the five conserved neural structures have proven to be successful in practice: 2. RBF 1-29-1, 3. RBF 1-29-1 and 5 . RBF 1-29-1. If we look at the performance in terms of the correlation coefficient, it remains to use only the three neural networks mentioned here, between which there are practically no differences.

As Vochozka (2010) emphasised, the question is whether to continue developing evaluation methods based on mathematical and statistical methods, or to focus on other possibilities, such as neural networks. Magni (2005) also confirmed the assumption that models of artificial neural networks work better than decision trees in terms of degree of accuracy and as such can be used to predict financial performance. Furthermore, the author assured that multilayer perceptrons had a better predictive power than radial basis functions.

\section{Data and Methods}

According to the contribution of Vrbka et al. (2019), it is obvious that the RBF neural networks show better results when adjusting time series using RBF and MLP. Out of 10,000 generated artificial neural networks, 5 networks with the best characteristics were preserved. Only the RBF networks showed the five best characteristics. No MLP network was included among these artificial neural networks. If we paraphrase the aim of the paper, we come to two sub-goals:

Verify that Vrbka et al. (2019) results present a generally valid result.

To verify how MLPs lag behind the RBF in their performance in solving such a task.

To meet the goal, we will perform an experiment. We will proceed partly according to the methodology of Vrbka et al. (2019). At the same time, however, we deviate slightly from the original methodology at a certain stage. The data for analysis is available on the World Bank's website and others. Information on the trade balance between the United States of America ("USA") and the People's Republic of China ("PRC") will be used for the analysis. It will be the difference between total exports and imports between the two countries from the point of view of the USA. The time interval for which the data will be available is the monthly balance starting in January 1985 and ending in August 2018. This is 404 pieces of input data. The unit is billions of US dollars.

Descriptive characteristics of the data are given in Table 1.

Tab. 1: Datafile characteristics

\begin{tabular}{|l|r|r|}
\hline \multicolumn{1}{|c|}{ Statistics } & Month (Input var.) & Balance (Output (goal)) \\
\hline Minimum (Training) & $31,048.00$ & $-38,569.6$ \\
\hline Maximum (Training) & $43,313.00$ & 155.5 \\
\hline Average (Training) & $37,316.95$ & $-12,814.0$ \\
\hline Standard Deviation (Training) & $3,549.13$ & $11,337.5$ \\
\hline Minimum (Testing) & $31,138.00$ & $-34,989.5$ \\
\hline
\end{tabular}




\begin{tabular}{|l|r|r|}
\hline Maximum (Testing) & $42,948.00$ & -17.7 \\
\hline Average (Testing) & $36,651.48$ & $-11,114.8$ \\
\hline Standard Deviation (Testing) & $3,758.45$ & $12,253.4$ \\
\hline Minimum (Validation) & $31,199.00$ & $-34,518.0$ \\
\hline Maximum (Validation) & $42,979.00$ & -67.8 \\
\hline Average (Validation) & $37,060.87$ & $-11,574.6$ \\
\hline Standard Deviation (Validation) & $5,186.49$ & $11,435.8$ \\
\hline Minimum (Overall) & $31,048.00$ & $-38,569.6$ \\
\hline Maximum (Overall) & $43,313.00$ & 155.5 \\
\hline Average (Overall) & $37,180.08$ & $-12,377.6$ \\
\hline Standard Deviation (Overall) & $3,554.16$ & $11,419.3$ \\
\hline
\end{tabular}

Source: Authors.

Figure 1 therefore shows the graphical form of selected statistical characteristics, including the histogram of the input data.

Figure 1: Graph of basic statistical characteristics

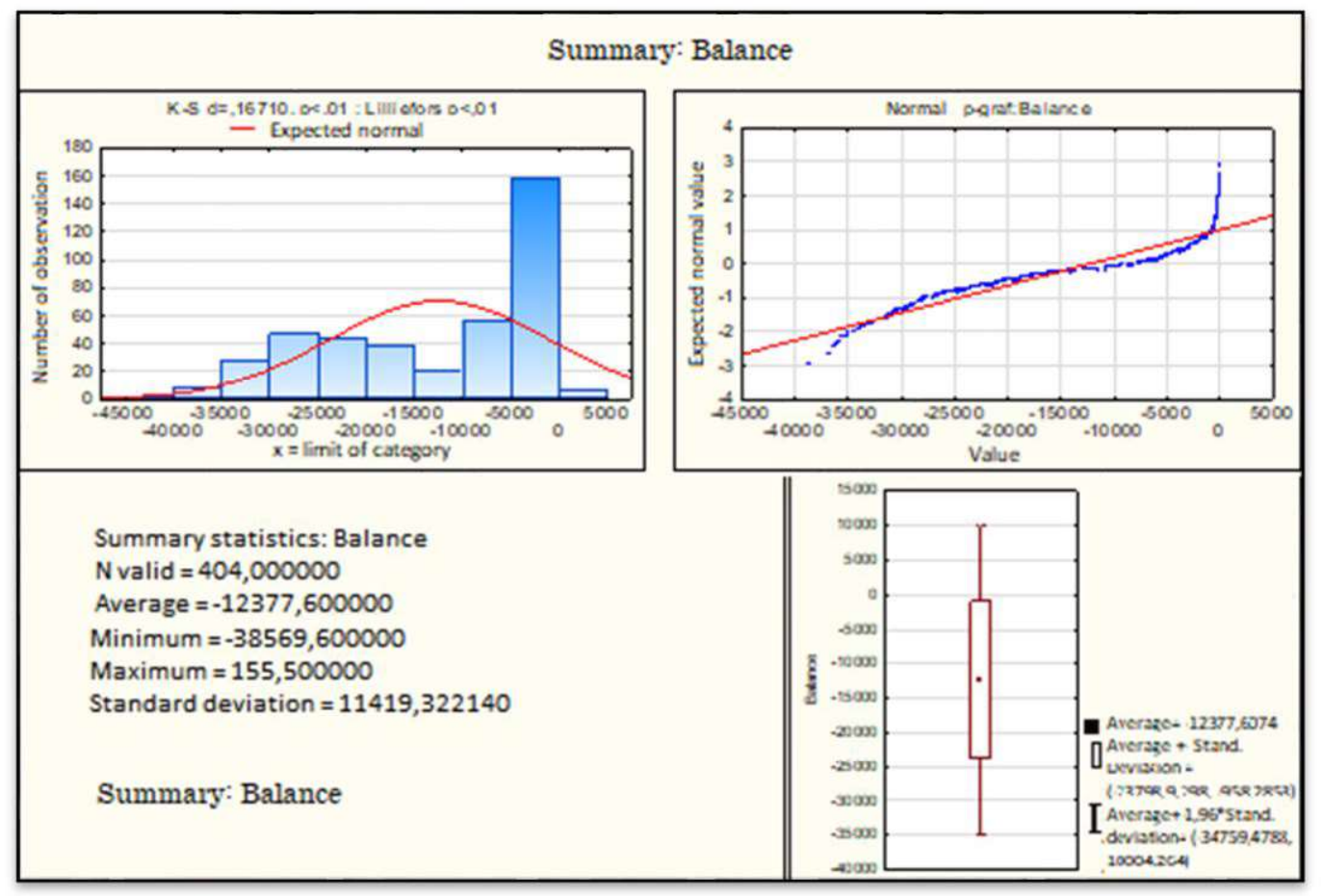

Source: Authors.

It is interesting how the histogram does not correspond to the normal distribution. Statistica software version 12 from DELL will be used for data processing.

Regression will be performed using neural structures. We will generate multilayer perceptron networks and neural networks of radial basis function. We will generate two sets of artificial neural networks. Time will be the continuous independent variable. We will determine the trade balance of the USA and the PRC as a dependent variable.

We will divide the time series into three files - training, testing and validation. The first group will contain $70 \%$ of the input data. Based on the training data set, we generate 
neural structures. In the remaining two data sets, we always leave $15 \%$ of the input information. Both groups will be used to verify the reliability of the found neural structure, or the found model. The time series delay will be 1 . We will generate 100,000 neural networks. In this we differ from Vrbka et al. (2019). We will generate ten times as many networks. The aim is a greater degree of accuracy. We will keep 5 of them, which show the best characteristics. The first results will respect the creation of both MLP and RBF networks. In the second case, we will only create MLP networks. We will have at least two neurons in the hidden layer, a maximum of 50. In the case of the radial basis function there will be at least 21 neurons in the hidden layer, at most 30. For multilayer perceptron network, we will consider the following distribution functions in the hidden layer and in the output layer:

- Linear,

- Logistic,

- Atanh,

- Exponential,

- $\quad$ Sinus.

We will leave the other settings as default (according to the ANS tool - automated neural networks).

Finally, we compare the results of both groups of preserved neural networks.

\section{Results}

\section{Neural structures A}

Based on the established procedure, 10,000 neural networks were generated. Of these, 5 networks were preserved, which show the best parameters. Their overview is given in table number 2 .

Tab. 1: Overview of preserved neural networks

\begin{tabular}{|c|c|c|c|c|c|c|c|c|c|c|c|}
\hline $\begin{array}{c}\text { Inde } \\
x\end{array}$ & $\begin{array}{c}\text { Network } \\
\text { name }\end{array}$ & $\begin{array}{c}\text { Training } \\
\text { perf. }\end{array}$ & $\begin{array}{l}\text { Testing } \\
\text { perf. }\end{array}$ & $\begin{array}{l}\text { Validatio } \\
\text { n perf. }\end{array}$ & $\begin{array}{l}\text { Trainin } \\
\text { g error }\end{array}$ & $\begin{array}{l}\text { Testing } \\
\text { error }\end{array}$ & $\begin{array}{l}\text { Validatio } \\
\text { n error }\end{array}$ & $\begin{array}{c}\text { Training } \\
\text { algorithm }\end{array}$ & $\begin{array}{l}\text { Error } \\
\text { function }\end{array}$ & $\begin{array}{l}\text { Activ. of } \\
\text { hidden } \\
\text { layer }\end{array}$ & $\begin{array}{l}\text { Output } \\
\text { activ. } \\
\text { funct. }\end{array}$ \\
\hline 1 & RBF $1-22-1$ & 0.976717 & 0.990200 & 0.981291 & 2934406 & 1486327 & 2303652 & RBFT & $\begin{array}{r}\text { Sum of } \\
\text { sq.. }\end{array}$ & Gauss & Identity \\
\hline 2 & RBF 1-21-1 & 0.980752 & 0.994040 & 0.981226 & 2429586 & 1528877 & 2305187 & RBFT & $\begin{array}{r}\text { Sum of } \\
\text { sq.. }\end{array}$ & Gauss & Identity \\
\hline 3 & RBF 1-29-1 & 0.980805 & 0.991049 & 0.983911 & 2422931 & 1506385 & 1945204 & RBFT & $\begin{array}{r}\text { Sum of } \\
\text { sq.. }\end{array}$ & Gauss & Identity \\
\hline 4 & RBF $1-25-1$ & 0.979270 & 0.991914 & 0.981607 & 2614728 & 1343300 & 2402934 & RBFT & $\begin{array}{r}\text { Sum of } \\
\text { sq.. }\end{array}$ & Gauss & Identity \\
\hline 5 & RBF 1-24-1 & 0.979458 & 0.991623 & 0.980938 & 2591340 & 1413482 & 2353812 & RBFT & $\begin{array}{r}\text { Sum of } \\
\text { sq.. }\end{array}$ & Gauss & Identity \\
\hline
\end{tabular}

Source: Authors.

These are only neural networks of the radial basis function. There is only one variable in the input layer - time. In the hidden layer, neural networks contain from 21 to 29 neurons. In the output layer, we logically have a single neuron and a single output variable, the trade balance of the USA and the PRC. The RBFT training algorithm was applied to all networks. In addition, all neural structures used the same function, namely the Gaussian 
curve, to activate the hidden layer of neurons. They also use the same function to activate the outer layer of neurons, namely an identity function (see Table 2 for more details).

Training, testing and validation performance is definitely also interesting. In general, we are looking for a network that has ideally the same performance in all data sets (we remind you that the division of data into sets took place randomly). The error should be as little as possible.

The performance of individual data sets is given in the form of a correlation coefficient. The values of individual data sets according to specific neural networks are given in table number 3.

Tab. 3: Correlation coefficients of individual data sets

\begin{tabular}{|c|r|r|r|}
\hline $\begin{array}{c}\text { Neural } \\
\text { network }\end{array}$ & Balance (Training) & Balance (Testing) & $\begin{array}{c}\text { Balance } \\
\text { (Validation) }\end{array}$ \\
\hline 1.RBF 1-22-1 & 0.976717 & 0.990200 & 0.981291 \\
\hline 2.RBF 1-21-1 & 0.980752 & 0.994040 & 0.981226 \\
\hline 3.RBF 1-29-1 & 0.980805 & 0.991049 & 0.983911 \\
\hline 4.RBF 1-25-1 & 0.979270 & 0.991914 & 0.981607 \\
\hline 5.RBF 1-24-1 & 0.979458 & 0.991623 & 0.980938 \\
\hline
\end{tabular}

Source: Authors.

The table shows that the performance of all preserved neural structures is approximately identical. Slight differences have no effect on the performance of individual networks. The value of the correlation coefficient of all training data sets ranges from more than 0.97 to more than 0.98 . The value of the correlation coefficient of the testing data sets reaches more than 0.99 for all neural networks. The correlation coefficient of the validation data set of all neural networks is above the level of 0.98 . In order to select the most suitable neural structure, we must perform a closer analysis of the obtained results. Table 4 offers the basic statistical characteristics of individual data sets for all neural structures.

Tab. 2: Statistics of individual data sets according to preserved neural structures

\begin{tabular}{|c|c|c|c|c|c|}
\hline Statistics & 1. RBF 1-22-1 & 2. RBF 1-21-1 & 3. RBF 1-29-1 & 4. RBF 1-25-1 & 5. RBF 1-24-1 \\
\hline Minimum prediction (Training) & $-33,729.8$ & $-32,812.1$ & $-35,611.6$ & $-30,887.5$ & $-32,039.2$ \\
\hline Maximum prediction (Training) & 385.0 & 202.7 & 465.0 & 312.0 & 312.4 \\
\hline Minimum prediction (Testing) & $-33,279.1$ & $-31,325.5$ & $-31,741.1$ & $-30,826.9$ & $-31,946.5$ \\
\hline Maximum prediction (Testing) & 275.2 & 162.1 & 464.2 & 168.6 & 294.9 \\
\hline Minimum prediction (Validation) & $-33,365.7$ & $-31,632.1$ & $-31,812.1$ & $-30,843.1$ & $-31,988.5$ \\
\hline Maximum prediction (Validation) & 298.4 & 24.6 & 392.5 & 201.5 & 218.5 \\
\hline Minimum residues (Training) & $-9,657.5$ & $-6,683.2$ & $-7,327.8$ & $-7,711.6$ & $-7,774.1$ \\
\hline Maximum residues (Training) & $9,716.2$ & $8,571.1$ & $8,882.7$ & $9,283.4$ & $10,189.8$ \\
\hline Minimum residues (Testing) & $-5,983.8$ & $-5,753.2$ & $-6,109.0$ & $-5,218.5$ & $-5,993.8$ \\
\hline Maximum residues (Testing) & $4,588.2$ & $2,638.7$ & $4,905.4$ & $3,590.0$ & $3,531.9$ \\
\hline Minimum residues (Validation) & $-6,164.3$ & $-5,445.2$ & $-5,767.4$ & $-4,992.1$ & $-6,785.3$ \\
\hline Maximum residues (Validation) & $6,573.3$ & $8,822.7$ & $5,667.2$ & $7,733.7$ & $7,408.2$ \\
\hline Minimum standard residues (Training) & -5.6 & -4.3 & -4.7 & -4.8 & -4.8 \\
\hline Maximum standard residues (Training) & 5.7 & 5.5 & 5.7 & 5.7 & 6.3 \\
\hline Minimum standard residues (Testing) & -4.9 & -4.7 & -5.0 & -4.5 & -5.0 \\
\hline
\end{tabular}


DOI: https://doi.org/10.36708/Littera_Scripta2020/2/3

\begin{tabular}{|l|r|r|r|r|r|}
\hline Maximum standard residues (Testing) & 3.8 & 2.1 & 4.0 & 3.1 & 3.0 \\
\hline Minimum standard residues (Validation) & -4.1 & -3.6 & -4.1 & -3.2 & -4.4 \\
\hline Maximum standard residues (Validation) & 4.3 & 5.8 & 4.1 & 5.0 & 4.8 \\
\hline
\end{tabular}

Source: Authors.

Ideally, the individual statistics of the neural network match cross-sectionally in all sets (minimums, maximums, residues, etc.). However, in the case of adjusted time series, the differences are minimal. Slightly larger differences are reflected in the characteristics of the residues. Nevertheless, we are not able to unambiguously determine which of the preserved neural networks shows the most suitable results. According to table number 4 , network 3. RBF1-29-1 may appear to be the most suitable.

Figure 8 is a line chart that presents the actual development of the trade balance of the USA and the PRC, as well as the development of forecasts using individual generated and preserved networks.

The chart shows that all neural networks predict the development of the trade balance at different intervals. However, it is not the similarity of the predictions of individual networks that is important, but the similarity (or degree of similarity) with the actual development of the trade balance. In this respect, too, it can be stated that all preserved neural networks look very interesting at first glance. They respect the directions of the curve assessing the development of the trade balance and at the same time tend to perceive the extremes of this curve. 
Figure 1: Line chart - development of the USA X PRC trade balance predicted by neural networks in comparison with the actual trade balance in the observed period



Source: Authors.

\section{Neural structures B}

Based on the established procedure, the second 100,000 neural networks were generated. Of these, 5 networks were again preserved, which show the best parameters. Their overview is given in table number 5 .

Tab. 3: Overview of preserved neural networks

\begin{tabular}{|r|c|r|r|c|r|r|r|r|r|r|r|}
\hline $\begin{array}{c}\text { Inde } \\
\mathbf{x}\end{array}$ & $\begin{array}{c}\text { Network } \\
\text { name }\end{array}$ & $\begin{array}{c}\text { Training } \\
\text { perf. }\end{array}$ & $\begin{array}{c}\text { Testing } \\
\text { perf. }\end{array}$ & $\begin{array}{c}\text { Validati } \\
\text { on perf. }\end{array}$ & $\begin{array}{c}\text { Training } \\
\text { error }\end{array}$ & $\begin{array}{c}\text { Testing } \\
\text { error }\end{array}$ & $\begin{array}{c}\text { Validation } \\
\text { error }\end{array}$ & $\begin{array}{c}\text { Training } \\
\text { algorithm }\end{array}$ & $\begin{array}{c}\text { Error } \\
\text { function }\end{array}$ & $\begin{array}{c}\text { Activ. of } \\
\text { hidd. } \\
\text { layer }\end{array}$ & $\begin{array}{c}\text { Output } \\
\text { activ. } \\
\text { funct. }\end{array}$ \\
\hline 1 & MLP 1-3-1 & 0.976462 & 0.991988 & 0.977570 & 2975860 & 1304652 & 2683213 & $\begin{array}{r}\text { BFGS (Quasi- } \\
\text { Newton) 60 }\end{array}$ & Sum of sq. & Tanh & Logistic \\
\hline 2 & MLP 1-2-1 & 0.977073 & 0.992287 & 0.977253 & 2888833 & 1327057 & 2697966 & $\begin{array}{r}\text { BFGS (Quasi- } \\
\text { Newton) 62 }\end{array}$ & Sum of sq. & Logistic & $\begin{array}{r}\text { Exponent } \\
\text { ial }\end{array}$ \\
\hline 3 & MLP 1-2-1 & 0.978396 & 0.992555 & 0.978855 & 2724112 & 1273146 & 2530060 & $\begin{array}{r}\text { BFGS (Quasi- } \\
\text { Newton) 86 }\end{array}$ & Sum of sq. & Tanh & Logistic \\
\hline 4 & MLP 1-6-1 & 0.972798 & 0.988162 & 0.977224 & 3557611 & 1995474 & 2934979 & $\begin{array}{r}\text { BFGS (Quasi- } \\
\text { Newton) 6 } 6\end{array}$ & Sum of sq. & Sinus & Tanh \\
\hline 5 & MLP 1-3-1 & 0.972993 & 0.988820 & 0.977645 & 3402392 & 2061365 & 2649306 & $\begin{array}{r}\text { BFGS (Quasi- } \\
\text { Newton) 27 }\end{array}$ & Sum of sq. & Sinus & Tanh \\
\hline
\end{tabular}

Source: Authors.

In line with the aim of this paper, these are only MLP networks. There is again only one variable in the input layer - time. In the hidden layer, neural networks contain 2 to 6 neurons. In the output layer we have a single neuron and a single output variable, i.e., the trade balance of the USA and the PRC. The Quasi-Newton training algorithm was applied to all networks. Neural structures used the sine, hyperbolic tangent and logistic functions to activate the hidden layer of neurons, and the logistic, exponential and hyperbolic tangent functions to activate the output layer (see Table 5 for more details). All preserved neural structures used the sum of least squares as the error function. 
The values of correlation coefficients expressing the performance of individual data sets according to specific neural networks are given in Table 6.

Tab. 4: Correlation coefficients of individual data sets

\begin{tabular}{|l|r|r|r|}
\hline $\begin{array}{c}\text { Neural } \\
\text { Network }\end{array}$ & Balance (Training) & Balance (Testing) & $\begin{array}{c}\text { Balance } \\
\text { (Validation) }\end{array}$ \\
\hline 1.MLP 1-3-1 & 0.976462 & 0.991988 & 0.977570 \\
\hline 2.MLP 1-2-1 & 0.977073 & 0.992287 & 0.977253 \\
\hline 3.MLP 1-2-1 & 0.978396 & 0.992555 & 0.978855 \\
\hline 4.MLP 1-6-1 & 0.972798 & 0.988162 & 0.977224 \\
\hline 5.MLP 1-3-1 & 0.972993 & 0.988820 & 0.977645 \\
\hline
\end{tabular}

Source: Authors.

The table shows that the performance of preserved neural structures differs only minimally. The value of the correlation coefficient of all training data sets ranges from more than 0.972 to more than 0.978 . The value of the correlation coefficient of the test data sets falls in the range from more than 0.988 to more than 0.992 . The correlation coefficient of the validation data set ranges from more than 0.977 to more than 0.978 . Based on the performance of individual data sets, all stored structures appear to be usable neural networks. In order to select the most suitable neural structure, we must perform a closer analysis of the obtained results. Table 7 offers the basic statistical characteristics of individual data sets for all neural structures.

Tab. 5: Statistics of individual data sets according to preserved neural structures

\begin{tabular}{|c|c|c|c|c|c|}
\hline Statistics & $\begin{array}{c}\text { 1.MLP 1-3- } \\
1\end{array}$ & $\begin{array}{l}\text { 2.MLP 1-2- } \\
1\end{array}$ & $\begin{array}{c}\text { 3.MLP 1-2- } \\
1\end{array}$ & $\begin{array}{c}\text { 4.MLP 1-6- } \\
1\end{array}$ & $\begin{array}{c}\text { 5.MLP 1-3- } \\
1\end{array}$ \\
\hline Minimum prediction (Training) & $-33,188.3$ & $-32,508.6$ & $-32,326.8$ & $-34,370.7$ & $-34,674.8$ \\
\hline Maximum prediction (Training) & -72.5 & 212.2 & -621.2 & 124.8 & -471.3 \\
\hline Minimum prediction (Testing) & $-31,992.2$ & $-31,504.4$ & $-31,652.8$ & $-32,049.5$ & $-31,909.1$ \\
\hline Maximum prediction (Testing) & -79.2 & 185.2 & -628.8 & 123.6 & -471.7 \\
\hline Minimum prediction (Validation) & $-32,097.0$ & $-31,592.4$ & $-31,715.0$ & $-32,227.4$ & $-32,122.6$ \\
\hline Maximum prediction (Validation) & -86.4 & 156.8 & -637.0 & 122.3 & -472.6 \\
\hline Minimum residues (Training) & $-7,515.6$ & $-7,532.1$ & $-6,966.7$ & $-8,132.8$ & $-9,098.3$ \\
\hline Maximum residues (Training) & $9,286.3$ & $9,067.3$ & $9,552.5$ & $8,637.7$ & $7,993.4$ \\
\hline Minimum residues (Testing) & $-5,516.0$ & $-5,641.1$ & $-5,083.1$ & $-6,225.7$ & $-7,023.1$ \\
\hline Maximum residues (Testing) & $4,033.0$ & $3,715.5$ & $3,416.7$ & $4,605.7$ & $3,832.2$ \\
\hline Minimum residues (Validation) & $-6,160.4$ & $-6,499.3$ & $-6,283.1$ & $-5,645.4$ & $-6,333.9$ \\
\hline Maximum residues (Validation) & $7,169.1$ & $7,188.7$ & $7,695.1$ & $6,669.0$ & $5,646.7$ \\
\hline Minimum standard residues (Training) & -4.4 & -4.4 & -4.2 & -4.3 & -4.9 \\
\hline Maximum standard residues (Training) & 5.4 & 5.3 & 5.8 & 4.6 & 4.3 \\
\hline Minimum standard residues (Testing) & -4.8 & -4.9 & -4.5 & -4.4 & -4.9 \\
\hline Maximum standard residues (Testing) & 3.5 & 3.2 & 3.0 & 3.3 & 2.7 \\
\hline Minimum standard residues (Validation) & -3.8 & -4.0 & -4.0 & -3.3 & -3.9 \\
\hline Maximum standard residues (Validation) & 4.4 & 4.4 & 4.8 & 3.9 & 3.5 \\
\hline
\end{tabular}

Source: Authors. 
Ideally, the individual statistics of the neural network match cross-sectionally in all sets (minimums, maximums, residues, etc.). Even this table shows only minimal differences at both absolute and residual values. Even at this stage, we are not able to unambiguously determine which of the preserved neural networks shows the most suitable results.

Figure 3 is a line chart that presents the actual development of the trade balance of the USA and the PRC, as well as the development of forecasts using individual generated and preserved MLP networks.

The chart shows the differences between reality and adjusted time series and at the same time between individual time series. All preserved MLP networks adjust the time series. In the case of the 3.MLP 1-2-1 network, an attempt can be made to identify two local extremes. Due to the beginning of the time series, 4.MLP 1-6-1 and 5.MLP 1-3-1 can be excluded from considerations regarding the use of preserved neural structures.

Figure 2: Line chart - development of the USA X PRC trade balance predicted by neural networks in comparison with the actual trade balance in the observed period

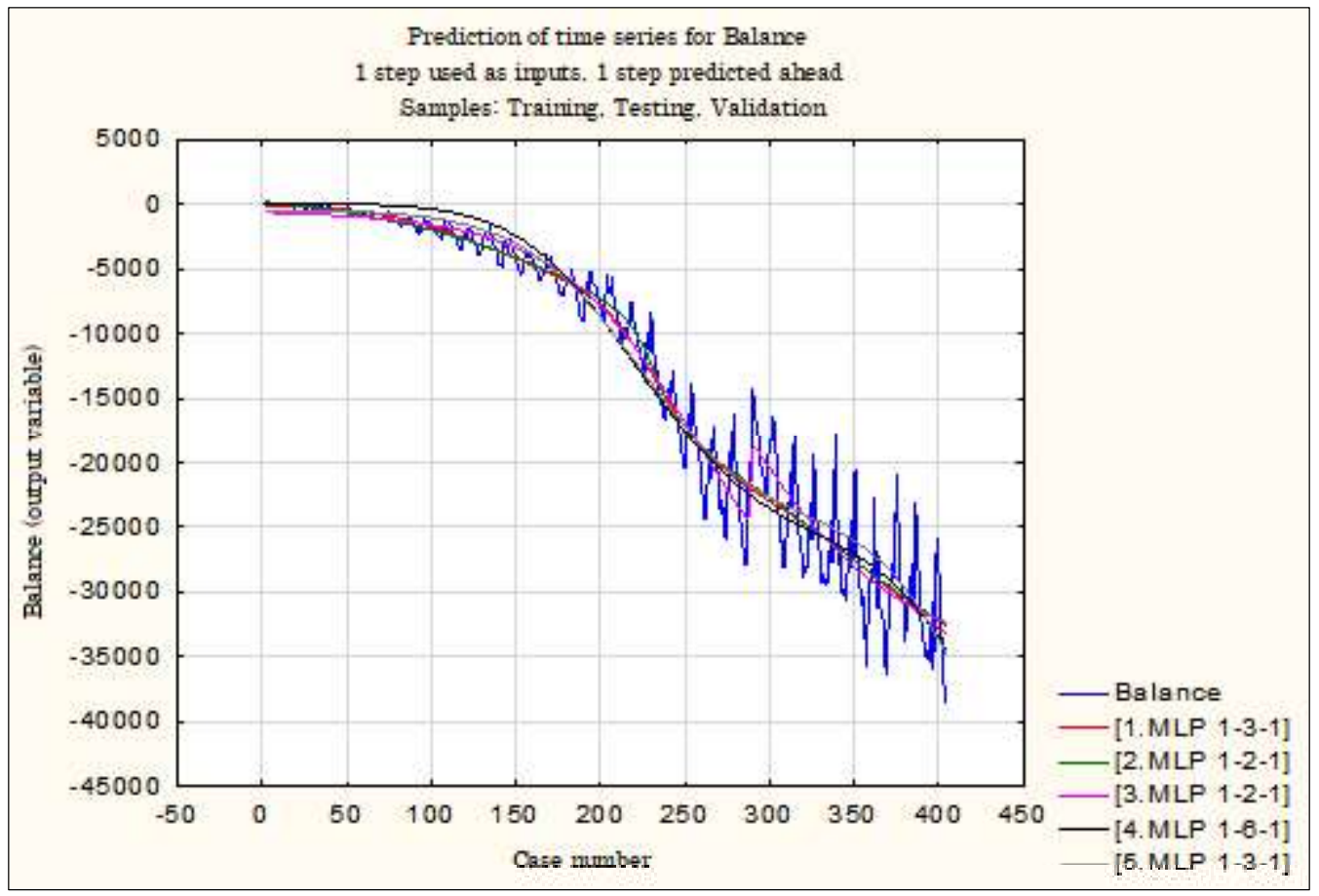

Source: Authors.

The remaining three neural networks give approximately the same power. These are 1.MLP 1-3-1, 2.MLP 1-2-1 and 3.MLP 1-2-1.

\section{Comparison of results between $A$ and $B$}

All generated and preserved artificial neural networks were able to adjust the examined time series - the trade balance of the USA and the PRC. The correlation coefficients of the individual sets, as quantified in Tables 3 and 6, foreshadow the minimum difference between the RBF and MLP networks. The differences of the correlation coefficients of the individual data sets are given in Table 8. 
Tab. 6: Differences in correlation coefficients of individual data sets of RBF and MLP networks

\begin{tabular}{|c|l|r|r|r|}
\hline $\begin{array}{c}\text { Line } \\
\text { number }\end{array}$ & \multicolumn{1}{|c|}{ Line name } & Balance (Training) & Balance (Testing) & Balance (Validation) \\
\hline 1 & 1. RBF 1-22-1 & 0.976717 & 0.990200 & 0.981291 \\
\hline 2 & 2. RBF 1-21-1 & 0.980752 & 0.994040 & 0.981226 \\
\hline 3 & 3. RBF 1-29-1 & 0.980805 & 0.991049 & 0.983911 \\
\hline 4 & 4. RBF 1-25-1 & 0.979270 & 0.991914 & 0.981607 \\
\hline 5 & 5. RBF 1-24-1 & 0.979458 & 0.991623 & 0.980938 \\
\hline 6 & 1. MLP 1-3-1 & 0.976462 & 0.991988 & 0.977570 \\
\hline 7 & 2.MLP 1-2-1 & 0.977073 & 0.992287 & 0.977253 \\
\hline 8 & 3. MLP 1-2-1 & 0.978396 & 0.992555 & 0.978855 \\
\hline 9 & $4 . M L P 1-6-1$ & 0.972798 & 0.988162 & 0.977224 \\
\hline 10 & $5 . M L P 1-3-1$ & 0.972993 & 0.988820 & 0.977645 \\
\hline 11 & l. $1-6$ & 0.000254 & -0.001788 & 0.003722 \\
\hline 12 & $1.2-7$ & 0.003679 & 0.001753 & 0.003973 \\
\hline 13 & $1.3-8$ & 0.002410 & -0.001506 & 0.005056 \\
\hline 14 & $1.4-9$ & 0.006473 & 0.003752 & 0.004383 \\
\hline 15 & $1.5-10$ & 0.006465 & 0.002803 & 0.003293 \\
\hline
\end{tabular}

Source: Authors.

From the generated neural networks, 5 artificial structures were always preserved. It can be assumed that the preserved networks were arranged in order from the one with the best characteristics to the one with the weakest characteristics (meaning only from the set of preserved neural networks). Therefore, to demonstrate the difference in network performance, the correlation coefficients of MLP networks in the same place in the order of the preserved networks were subtracted from the correlation coefficients of the RBF networks. According to the table, the differences are absolutely minimal, in the order of a fraction of thousandths. Nevertheless, with the exception of two differences, the results are positive. This means that RBF networks demonstrate, albeit very slightly, higher performance on all data sets than MLP networks. The situation is repeated when evaluating the basic statistics of predictions, adjusted time series, in Tables 4 and 7 . Preserved RBF networks, and their adjusted time series, show smaller differences in the set of training, testing and validation than in the case of MLP networks. All this is finally confirmed by Figures 2 and 3. Figure 4 summarises the course of all preserved neural networks and the actual course of the trade balance of the USA and the PRC. 
Figure 3: Comparison of preserved MLP and RBF networks



Source: Authors.

Not only from the figure, but also from previous analyses, it was possible to identify that the best networks between RBFs are 3.RBF 1-29-1 and 5.RBF 1-24-1. Among the MLPs, the best results are shown by the neural networks 1.MLP 1-3-1, 2.MLP 1-2-1 and 3.MLP 1-2-1. For a better overview, we will compare the two most successful neural networks from preserved sets (for more details, see Figure 5).

Figure 4: Comparison of the most successful preserved MLP and RBF networks

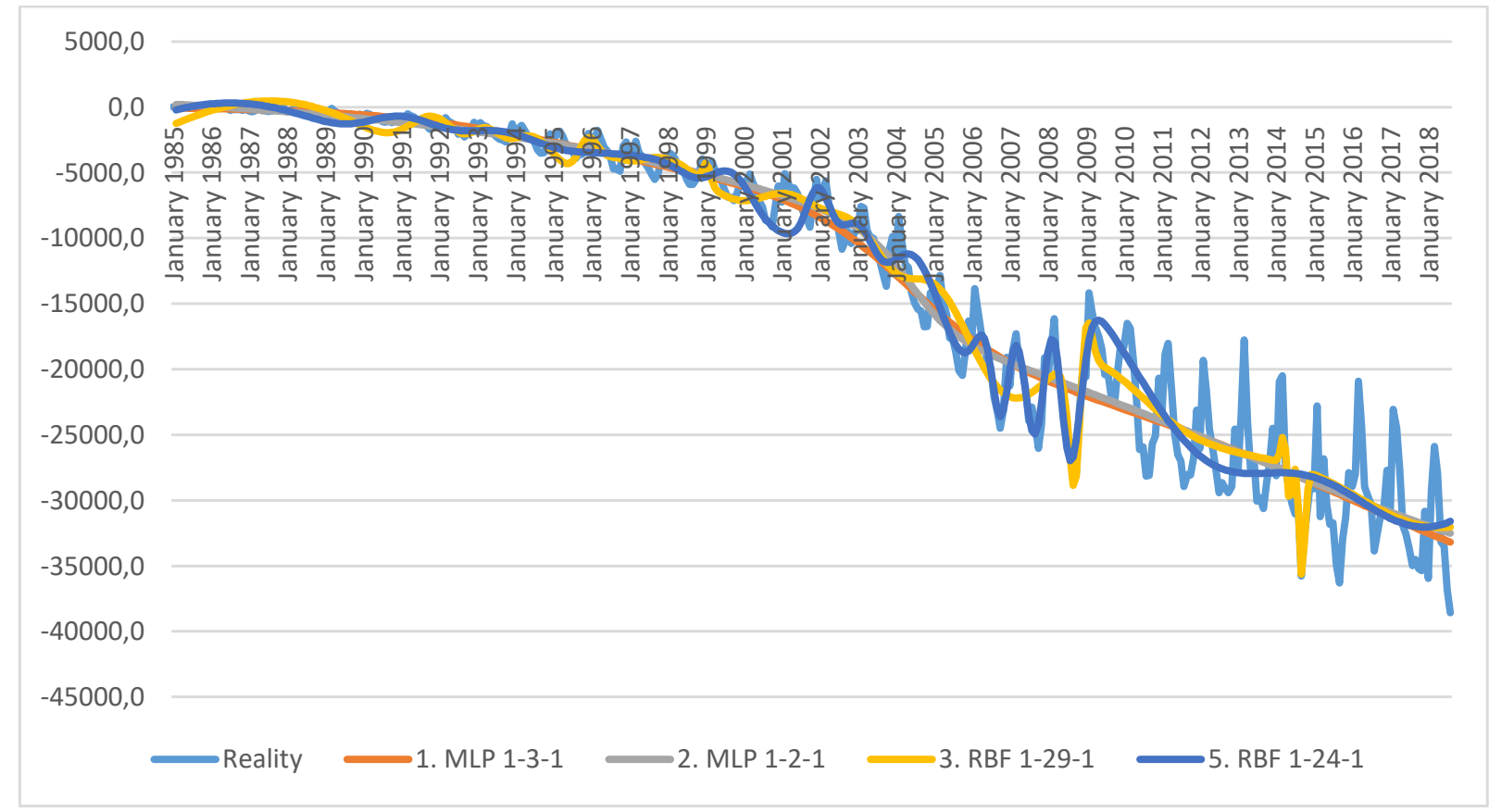

Source: Authors. 
At first glance, it is quite obvious that only RBF networks of variant A show a greater ability to affect the time series according to its actual course (and let us add that they affect the two compared RBF networks as well). On the contrary, both shown time series adjusted by MLP networks generate significantly larger residues, especially in the middle and final phase of the observed time period.

\section{Conclusion}

The aim of the paper was to analyse and evaluate the performance of multilayer neural networks (hereinafter referred to as "MLP") and neural networks of radial basis function (hereinafter referred to as "RBF") in adjusting time series using the trade balance of the United States and the People's Republic of China.

In general, each prediction is given a certain degree of probability with which it is fulfilled. When we predict the future development of any variable, we try to estimate the future development of this variable based on data from past periods. Although we can include most of the factors influencing the target quantity in the model, there is always a simplification of reality and we always work with a certain degree of probability that some of the scenarios we predict will come true.

We can state that due to the great simplification of reality, it is not possible to predict the emergence of extraordinary situations and their impact on the trade balance of the USA and the PRC (perhaps in the short term it is, in the long term certainly not). An ideal prediction would be for the order of days, but for such a short prediction it is not currently possible to obtain data.

To validate the result of Vrbka et al. (2019), we worked with a significantly greater degree of accuracy. In our experiment, we generated 100,000 and 100,000 artificial neural structures, respectively.

In our post, we have verified that:

the result of Vrbka et al. (2019) presents a generally valid result. When an adjusted time series is derived from a single variable, time, RBFs perform better than MLPs.

The trade balance of both countries can be determined on the basis of statistical methods, causal methods and intuitive methods. In this case, we compared two variants of the same statistical tool. However, they can only give us a possible framework for the development of the monitored variable. It is important to work with information on possible future developments in the economic, political or legal environment. If we are able to predict its development, we can then project it into the monitored trade balance. At the same time, however, it is the personality of the evaluator - an economist, who, based on their knowledge and experience, corrects the variable determined by general statistical methods and specified on the basis of causal links. In order to make the prediction more accurate and its calculation easier, it seems appropriate to use variant A (RBF networks), which brings a relatively high degree of accuracy. Specifically, the 3.RBF 1-29-1 and 5.RBF 
1-24-1 networks show very interesting results. At the same time, we must add that the result was not refined in generating ten times more neural networks in this experiment, before Vrbka et al. (2019) did.

The aim of the paper was fulfilled.

\section{References}

FAJARDO-TORO, C. H., L. A. COBO and P. M. T. MARTÍNEZ-SÁNCHEZ, 2019. Comparison of the behavior of recurrent neural networks against other methods to obtain time series forecasts. ISTI - Revista Iberica de Sistemas e Tecnologias de Informacao, (E17), p. 10221034. ISSN 1646-9895.

CHANG, T. S., 2011. A comparative study of artificial neural networks, and decision trees for digital game content stocks price prediction. Expert Systems with Applications. Cham: Springer International Publishing, 38(12), p. 14846-14851. Contributions to Economics. ISBN 978-3-030-11753-5. ISSN 0957-4174.

KLIEŠTIK, T., 2013. Models of autoregression conditional heteroscedasticity garch and arch as a tool for modeling the volatility of financial time series. Ekonomicko-Manažerské Spektrum, 7(1), p. 2-10. ISSN 1337-0839

LIU, Z. et al., 2009. Modelling and prediction of the CNY exchange rate using RBF neural network. 2009 International Conference on Business Intelligence and Financial Engineering, p. 38-41. ISBN 978-0-7695-3705-4.

MACHOVÁ, V. and M. VOCHOZKA, 2019. Using artificial intelligence in analyzing and predicting the development of stock prices of a subject company. Sustainable Growth and Development of Economic Systems. Cham: Springer International Publishing, (E17), p. 235245. Contributions to Economics. ISBN 978-3-030-11753-5. ISSN 1646-9895.

MAGNI, C. A., 2005. On decomposing net final values: EVA, SVA and shadow project. Theory and Decision, 59(1), p. 51-95. ISSN 0040-5833.

RODRIGUES, F., I. MARKOU and F. C. PEREIRA, 2019. Combining time-series and textual data for taxi demand prediction in event areas: A deep learning approach. Information Fusion, 49, p. 120-129. ISSN 1566-2535.

ROWLAND, Z., P. ŠULEŘ and M. VOCHOZKA, 2019. Comparison of neural networks and regression time series in estimating the Czech Republic and China trade balance. SHS Web of Conferences - Innovative Economic Symposium 2018: Milestones and Trends of the World Economy, 61. ISSN 2261-2424.

VOCHOZKA, M., 2017a. Effect of the economic outturn on the cost of debt of an industrial enterprise. SHS Web of Conferences - Innovative Economic Symposium 2017: Strategic Partnership in International Trade, 39. ISSN 2261-2424. 
VOCHOZKA, M., 2017b. Inventory management using artificial neural networks in a concrete case. Proceedings of the 5th International Conference Innovation Management, Entrepreneurship and Sustainability (IMES 2017). ISBN 978-80-245-2216-6.

VOCHOZKA, M. and P. SHENG, 2016. The application of artificial neural networks on the prediction of the future financial development of transport companies. Communications Scientific Letters of the University of Zilina, 18(2), p. 62-67. ISSN 1335-4205.

VOCHOZKA, M., 2010. Vývoj metod komplexního hodnocení výkonnosti podniku [Delelopment of methods for comprehensive evaluation of company performance]. Politická Ekonomie, 58(5), p. 675-688. ISSN 0032-3233.

VRBKA, J., Z. ROWLAND and P. ŠULEŘ, 2019. Comparison of neural networks and regression time series in estimating the development of the EU and the PRC trade balance. SHS Web of Conferences - Innovative Economic Symposium 2018: Milestones and Trends of the World Economy, 61. ISSN 2261-2424.

VRBKA, J. et al., 2019. Considering seasonal fluctuations in equalizing time series by means of artificial neural networks for predicting development of USA and People's Republic of China trade balance. Littera Scripta, 12(2), p. 178-193. ISSN 1805-9112.

WEDDING, D. K. and K. J. CIOS, 1996. Time series forecasting by combining RBF networks, certainty factors, and the Box-Jenkins model. Neurocomputing, 10(2), p. 149-168. ISSN 0925-2312.

ZHANG, G. P., A. F. CEBECI and S. Z. IMAMOGLU, 2001. An investigation of neural networks for linear time-series forecasting. Computational Economics, 28(12), p. 1183-1202. ISSN 0305-0548.

\section{Contact address to the authors:}

Ing. Jaromír Vrbka, MBA, PhD., Institute of Technology and Business, School of Expertness and Valuation, Okružní 517/10, 37001 České Budějovice, Czech Republic, email: vrbka@mail.vstecb.cz

Mgr. Petr Šuleř, PhD., Institute of Technology and Business, School of Expertness and Valuation, Okružní 517/10, 37001 České Budějovice, Czech Republic, e-mail: 24786@mail.vstecb.cz

Ing. Veronika Machová, MBA, Institute of Technology and Business, School of Expertness and Valuation, Okružní 517/10, 37001 České Budějovice, Czech Republic, email: machova@mail.vstecb.cz

Ing. Jakub Horák, MBA, Institute of Technology and Business, School of Expertness and Valuation, Okružní 517/10, 37001 České Budějovice, Czech Republic, email: $\underline{\text { horak@mail.vstecb.cz }}$ 